\title{
Neural Correlates of Hand-Object Congruency Effects during Action Planning
}

\author{
Zuo Zhang ${ }^{1}$ (i) , Peter Zeidman ${ }^{2}$, Natalie Nelissen ${ }^{3}$, Nicola Filippini ${ }^{4}$, Jörn Diedrichsen ${ }^{5}$, \\ Stefania Bracci ${ }^{6}$, Karl Friston ${ }^{2}$, and Elisabeth Rounis ${ }^{4,7}$
}

\begin{abstract}
Selecting hand actions to manipulate an object is affected both by perceptual factors and by action goals. Affordances may contribute to "stimulus-response" congruency effects driven by habitual actions to an object. In previous studies, we have demonstrated an influence of the congruency between hand and object orientations on response times when reaching to turn an object, such as a cup. In this study, we investigated how the representation of hand postures triggered by planning to turn a cup was influenced by this congruency effect, in an fMRI scanning environment. Healthy participants were asked to reach and turn a real cup that was placed in front of them either in an upright orientation or upside-down. They were instructed to use a hand orientation that was either congruent or incongruent with the cup orientation. As expected, the motor responses were faster
\end{abstract}

\section{INTRODUCTION}

When planning to grasp an object, we are faced with an infinite number of combinations of arm postures and movements we could use (Wolpert, 1997; Bernstein, 1967). There is converging evidence that action selection is governed by two distinct mechanisms: a goal-directed system and a habitual system (Hardwick, Forrence, Krakauer, \& Haith, 2019; Dolan \& Dayan, 2013; Balleine \& Dickinson, 1998), leading us to engage in highly stereotyped movements to achieve a given goal (Harris \& Wolpert, 1998; Keele, 1968).

A "goal-directed" system selects actions based on an evaluation of anticipated outcomes in relation to current needs. This can be demonstrated in the choice of trajectories when manipulating an object (Harris \& Wolpert, 1998; Wolpert, 1997; Bernstein, 1967). One example, the "end state comfort" effect, describes the preference for participants to start an action uncomfortably with a plan to use an intrinsically familiar trajectory to achieve an action goal, leading to a comfortable posture at the end (Rosenbaum, Vaughan, Barnes, \& Jorgensen, 1992; Rosenbaum et al.,

\footnotetext{
${ }^{1}$ King's College London, ${ }^{2}$ University College London, ${ }^{3}$ University of Leeds, ${ }^{4}$ University of Oxford, ${ }^{5}$ University of Western Ontario, ${ }^{6}$ University of Trento, ${ }^{7}$ West Middlesex University Hospital, Isleworth
}

when the hand and cup orientations were congruent. There was increased activity in a network of brain regions involving objectdirected actions during action planning, which included bilateral primary and extrastriate visual, medial, and superior temporal areas, as well as superior parietal, primary motor, and premotor areas in the left hemisphere. Specific activation of the dorsal premotor cortex was associated with hand-object orientation congruency during planning and prior to any action taking place. Activity in that area and its connectivity with the lateral occipitotemporal cortex increased when planning incongruent (goaldirected) actions. The increased activity in premotor areas in trials where the orientation of the hand was incongruent to that of the object suggests a role in eliciting competing representations specified by hand postures in lateral occipito-temporal cortex.
1990). Conversely, a "habitual" system selects actions in relation to stimulus-response associations that have been successful in the past. Whereas the former system is activated slowly and is computationally intensive, allowing adaptation to changes in the environment or task conditions, the latter is activated rapidly, inflexibly and may lead to perseveration on actions that are no longer appropriate (Hardwick et al., 2019).

Gibson (1979) introduced the term "affordance" to describe latent action possibilities offered by an object that are independent of the ability to recognize them but relate to the actor's motor capabilities (Bub, Masson, \& Kumar, 2018; Friston et al., 2012; Gibson, 1979). Initial studies reported that "affordances" led to stimulus-response compatibility effects based on a correspondence between the graspable features of objects depicted in 2-D images and "independent" task-related actions (Bub \& Masson, 2010; Creem \& Proffitt, 2001; Craighero, Fadiga, Umiltà, \& Rizzolatti, 1996; Gentilucci \& Gangitano, 1998; Tucker \& Ellis, 1998). However, the purported "automatic" activation of habitual actions elicited by affordances has been widely debated with recent evidence in the literature suggesting that these effects are dependent on task and stimulus sets (Kornblum \& Lee, 1995), and on the type of motor response required to be executed (Bub, Masson, \& van Noordenne, 2021; Chong \& Proctor, 2020; Bub 
et al., 2018; Bub \& Masson, 2010). As a result, habitual actions have been shown to be more strongly elicited with real objects than 2-D images of objects (Gomez, Skiba, \& Snow, 2018; Snow et al., 2011). In a study by Creem and Proffitt (2001), participants were observed to grasp objects by their functional side (e.g., their handle, in the case of a saucepan), when performing a dual-visuospatial task, but not when performing a dual-semantic task, suggesting that habitual actions elicited by affordances may include conceptual knowledge about objects rather than simple visuospatial mappings (Bub et al., 2018; Creem \& Proffitt, 2001).

Most previous studies have investigated habitual and goal-directed systems separately, using different stimuli. For example, goal-directed studies testing the "end-state comfort" effect have used objects that are neutral, such as bars, requiring different reach and grasp actions based on specified instructions (Herbort \& Butz, 2011; Rosenbaum et al., 1992), whereas studies testing habitual behavior have involved responses to 2-D images of an object using actions that are often unrelated to object use, such as a keypress (Tucker \& Ellis, 1998). As mentioned above, several of these studies have led to contradictory findings, with more recent evidence suggesting that these "affordance effects" depend on motor intentions (Bub et al., 2021). Investigating these effects with reach-and-grasp actions on real objects provides a more ecologically valid paradigm to study their interactions (Chong \& Proctor, 2020; Herbort \& Butz, 2011; Rounis, Zhang, Pizzamiglio, Duta, \& Humphreys, 2017).

There is increasing evidence to suggest that both habitual and goal-directed systems interact with one another, in behavioral studies in humans (Pizzamiglio, Zhang, Duta, \& Rounis, 2020; Hardwick et al., 2019; Herbort, Mathew, \& Kunde, 2017; Rounis et al., 2017; Herbort \& Butz, 2011), during development (Ossmy et al., 2020) as well as in patients (Pizzamiglio et al., 2020; McBride, Sumner, \& Husain, 2012; Riddoch, Edwards, Humphreys, West, \& Heafield, 1998). In recent studies, we and others have demonstrated situations in which habitual actions triggered by affordances trump goal-directed actions predicted by the end state comfort effect, during object manipulation. Herbort and Butz (2011) showed that when participants are asked to turn a cup from its upright position, upside-down, they often favor a hand posture that is compatible with the object orientation and typically grasp it from its top (or open end), even though this would lead an uncomfortable posture in the end, thus contradicting the choice of grasp predicted by "end state comfort effect." Our group corroborated this finding by demonstrating evidence that even if participants are asked to perform these actions on a cup in a forced choice task, their RTs are shorter in conditions where the hand and cup orientation are congruent ("afforded," i.e., habitual), compared to when they are incongruent (Pizzamiglio et al., 2020; Rounis et al., 2017). Given evidence that these processes are separable behaviorally, we asked, in this study, whether they may be mediated by separable neural substrates (Pizzamiglio et al., 2020; Rounis et al., 2017; Herbort \& Butz, 2011; Daprati \& Sirigu, 2006; Waszak et al., 2005; Balleine \& Dickinson, 1998; Owen, 1997).

Previous functional imaging studies have reported the neural correlates of actions directed to real objects in the scanner. These have mostly contrasted between different actions (Gallivan, McLean, Flanagan, \& Culham, 2013; Gallivan, McLean, Smith, \& Culham, 2011; Valyear, CavinaPratesi, Stiglick, \& Culham, 2007), or between different objects (Sakreida et al., 2016). Very few functional imaging studies have investigated the neural correlates of habitual actions elicited by "affordances" in healthy volunteers (Kumar, Yoon, \& Humphreys, 2012; Grèzes, Tucker, Armony, Ellis, \& Passingham, 2003), which is at odds with the extensive body of behavioral literature of this effect. Moreover, they have not contrasted the neural correlates of "affordancemediated" habitual actions against goal-directed actions.

In this study, we explored the neural underpinnings of hand-object congruency effects, when planning to turn a cup within an fMRI environment (Rounis et al., 2017). A handleless cup was placed either upright or upside-down, for participants to turn either using a supinated ("straight") or a pronated ("invert[ed]") hand grasp. Based on our previous results, we expected to find that grasps in which the cup and hand orientation were congruent (i.e., "afforded") would be faster because they are habitual. At the neural level, we investigated regional brain activations during motor planning, to reveal how congruency between the hand and the cup influenced areas involved in object manipulation (Gallivan, McLean, Valyear, \& Culham, 2013; Verhagen, Dijkerman, Medendorp, \& Toni, 2012; Gallivan et al., 2011; Grol et al., 2007; Mahon et al., 2007; Daprati \& Sirigu, 2006) prior to any movement taking place.

\section{METHODS \\ Participants}

Twenty-seven healthy righted-handed volunteers were recruited to participate in this study (14 women, 13 men; mean age $=27.95$ years; age range $=20-38$ years). All participants had normal or corrected-to normal vision. Full written consent according to the Declaration of Helsinki was obtained from all participants. The study was approved by Oxford University's Central University Research Ethics Committee (MS-IDREC-C1-2015-097). Participants were compensated $110 / \mathrm{hr}$ or course credits for participating in the experiment. Data from two participants were discarded because technical issues caused the behavioral and timing data not to be recorded. The study procedures or analyses were not preregistered prior to the research.

\section{Experimental Setup}

Participants performed an instructed-delay cupmanipulation task while lying supine in the MRI scanner. 
In this task, the cup "manipulation" involved the action of reaching to and turning the cup from an upright position upside-down, or vice versa. Previous studies implicate different brain regions associated with moving an object, as opposed to using it (Daprati \& Sirigu, 2006).

The standard mattress of the scanner bed was replaced by a thinner one, allowing participants to lie lower within the scanner bore so that they could comfortably bend their head to look at the object positioned on a custom-made Perspex platform in front of them. Their head was positioned inside a phased array receiver 12 -channel MRI headcoil, which rested on a $15^{\circ}$ wedge (Figure 1 ). Participants' overall head tilt was $25^{\circ}$ from supine, considering the width of the headcoil and padding provided, which lifted their head further inside it. This allowed for direct visualization of the cup to be grasped and visual control of their hand movement.

Participants performed actions with their right hand and had the upper arm immobilized using a wedge-shaped elbow foam pad positioned against their side and the side of the scanner bore, in front of the Perspex table, which was positioned above their lap, and was secured with pegs that were fitted in the side of the scanner bed (Figure 1). The pad and Perspex table constrained participants' arm movement to rotate around the elbow and wrist. A "home" key and cup (target object) were positioned on the Perspex table. The cup was positioned on a cupholder that formed a dent on the Perspex table. This and the home key button were fitted with sensors allowing the measurement of times at which the home key was pressed, or the cup was lifted from (and reposition onto) the cupholder.
A custom-made handleless transparent cylindrical cup, measuring $10.5 \mathrm{~cm}$ in height and $7.8 \mathrm{~cm}$ in diameter and shaped to be perceived as upright or down, was positioned on the cupholder. Participants were instructed to rest their hand on the home key button all the time except when they were due to perform an action. This allowed the measurement of the action initiation and its ending, when the hand was lifted from its resting position on the home key, to its return after having turned the cup as instructed. The cupholder was positioned at an average distance of $50 \mathrm{~cm}$ from the participants' eyes, adjusted to match each participant's arm length such that all movements were comfortable (Gallivan et al., 2011; Culham, 2004). The cup subtended a vertical visual angle averaging $10^{\circ}$ in front of participants at a point corresponding to each participant's sagittal midline. The home key was positioned an average of $20 \mathrm{~cm}$ to the right side of the cup.

The timely appearance of the cup was controlled by liquid crystal MRI-compatible, PLATO occlusion spectacles (Translucent Technologies), which participants wore throughout the experiment. These allowed the timely initiation and end of each trial, and obstructed participants' vision between trials. Experimental conditions, timings, and recording of movement-related responses were controlled using a personal computer running Presentation 15.0 (Neurobehavioral Systems).

Of note, our choice of using a handleless cup in this experiment was to remove a confound that has led to previous debates as to whether affordance effects relate to visuospatial attention, compare the Simon effect (Simon, 1969), or whether it constitutes the elicitation of

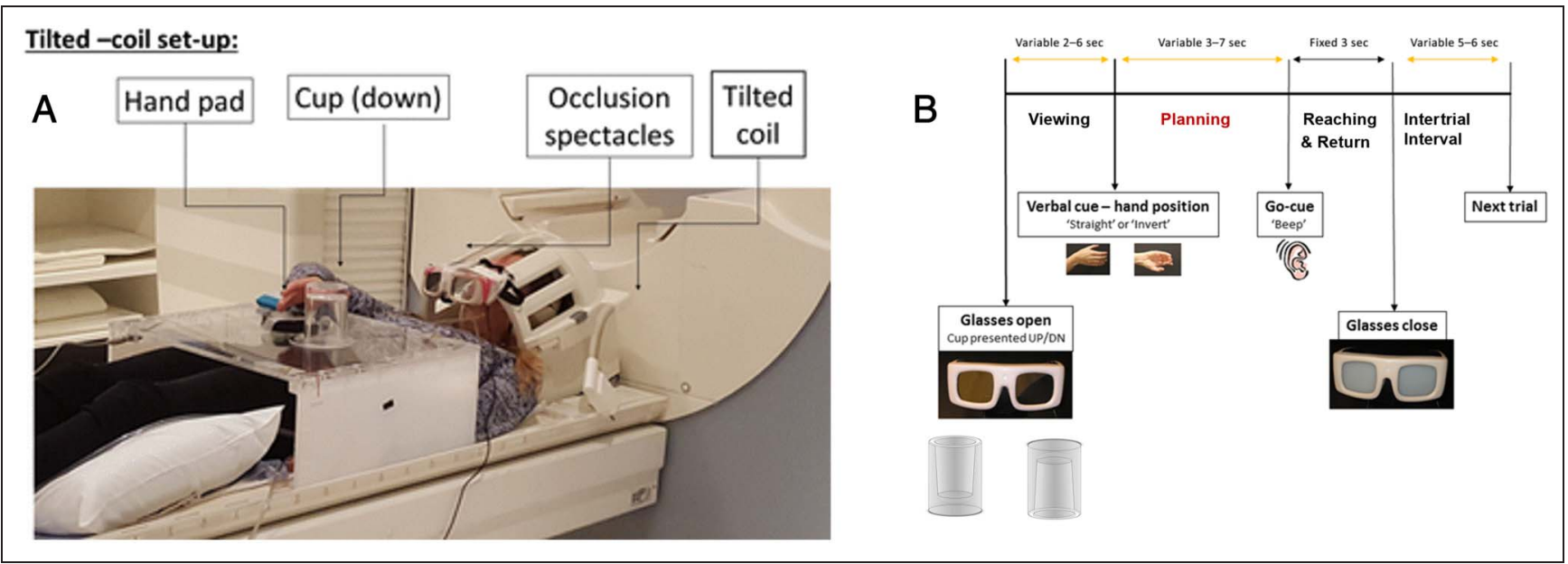

Figure 1. fMRI setup and timings. (A) Experimental setup. Example of a setup from one participant (video of example trial provided separately). The participant laid supine with their head on a 12-channel tilted coil (external tilt angle provided by $15^{\circ}$ wedge, with another $10^{\circ}$ tilt provided by padding in the head coil). They wore PLATO occlusion spectacles, which were positioned at the edge of the coil here for ease of visualization. The participant is pictured lifting their hand from the home key (black button) to pick up the cup that is positioned upside-down and turn it upright, on the cupholder. (B) Timings. The viewing phase started with PLATO glasses turning transparent. After a variable delay, a verbal instruction lasting 0.5 sec followed, which said "straight" or "invert" indicated the start of the planning phase, during which participants maintained their hand on the home key until they heard a go cue (a "beep," also lasting $0.5 \mathrm{sec}$ ), which followed after a variable delay from the verbal instruction. At this point ("reaching" time) participants lifted their hand from the home key (RT) to reach and turn the cup before returning to the home key. They were instructed to complete the action within a fixed time of $3 \mathrm{sec}$, indicated by the glasses becoming opaque. Modeling of the GLM based on these timings is detailed in the text. The imaging results presented in this study relate to the planning phase, highlighted in red. 
motor representations (Cho \& Proctor, 2013; Wilf, Holmes, Schwartz, \& Makin, 2013). In our task, the congruency effect was not specified by the handle of a cup, but rather by its position being upright or down, which would habitually elicit a supinated or pronated grasp, respectively (Pizzamiglio et al., 2020; Pazzaglia \& Galli, 2019; Rounis et al., 2017; Herbort \& Butz, 2011). Previous studies have demonstrated hand-object compatibility effects differ according to whether the object location is centered (Bub et al., 2018; Cho \& Proctor, 2013). There is literature to explain these behavioral effects in terms of differences between "motor" and "orienting" attention, the former being elicited when single objects are presented at the center of vision removing confounds of oculomotor and visuospatial responses (Rounis, Yarrow, \& Rothwell, 2007; Rushworth, Ellison, \& Walsh, 2001). Motor attention involves dorsal visuomotor networks centered in the anterior parietal region and is left-lateralized with deficits leading to ideomotor apraxia (Rushworth, Nixon, Renowden, Wade, \& Passingham, 1997). Based on this, we conjectured that affordance effects obtained from this object would not be attributable to an orienting process because the object and responses in our task were centrally located (Bub et al., 2018; Rounis et al., 2007).

\section{Experimental Time Course and Procedures}

In this task, participants had to grasp the cup with their right hand and turn it either from an upright orientation to upside-down or vice versa. An event-related design averaging 8-16 sec per trial was used to isolate visuomotor response for planning from motor execution responses, as has been done in other object-in-the-scanner experiments (Gallivan, McLean, Valyear, et al., 2013; Gallivan et al., 2011). Each trial was preceded by a variable period (with a variable intertrial interval of 5-6 sec) in which participants had the spectacles switched off (opaque) and their right hand resting on the home key. This time allowed an experimenter, who was with the participant in the scanning room, to position the cup on the cupholder either in an upright or upside-down orientation according to a random order of conditions (determined to ensure equal repetitions of each trial type). During a trial, the experimenter was never visible to the participant when the glasses were open. The experimenter monitored performance in each trial and recorded any errors. Each trial condition was provided to the experimenter from instructions presented on a screen that was visible to them from the control room. These were not visible to the participants lying in the scanner bed.

Each trial began with the liquid spectacles turning transparent (open), allowing the participant to visualize the cup either in its upright or upside-down position (the "viewing" phase). After a random time interval of 2-6 sec, a verbal cue instructed the participant to either grasp the cup with a pronated or a supinated grasp. The verbal cue lasted $0.5 \mathrm{sec}$ and consisted of the word "invert" (for pronated grasp) or "straight" (for supinated grasp). This verbal cue corresponded to the onset of the "planning" phase. During both these intervals, participants continued to rest their hand on the home key. After a further variable duration of 3-7 sec, a beep signal (0.5-sec duration) was delivered. This corresponded to a "go cue," indicating that participants had to execute the movement instructed in the "planning" phase. At the go cue, participants lifted their right hand from the home key as quickly as possible, to reach and grasp the cup either with a "straight" or an "inverted" grasp (in the manner instructed by the verbal cue at the planning phase) and executed the action before returning to the home key, within a fixed interval of $3 \mathrm{sec}$, denoted when the translucent spectacles turned opaque. When participants heard the go cue, they executed the cup manipulation task instructed by the verbal cue presented during the "planning" phase. If they heard "straight," participants grasped the cup using a "thumbup," supinated, wrist posture and turned it with a pronation, leading to an uncomfortable "thumb-down" position. If they heard "invert" during the "planning" phase, participants grasped the cup using a "thumb-down" pronated wrist posture and turned it with a supination to a comfortable "thumb-up" end state. The execution phase ended with the spectacles becoming opaque (closed) after a fixed duration of $3 \mathrm{sec}$, before a further variable intertrial interval of 5-6 sec followed, during which the cup was repositioned by the experimenter, according to the next trial's condition.

The variable durations for each phase mentioned above (namely, the intertrial interval, "viewing," and "planning" phases) were drawn from a geometric distribution ( $p=$ .2) in steps of $0.5 \mathrm{sec}$. The reason for introducing a variable time between each of these intervals was to make the auditory instruction unexpected, based on behavioral pilots.

Participants completed 10 runs of 24 trials each (4 conditions $\times 6$ trials per condition) in one fMRI session (total of 240 trials), lasting 45-60 min. The order of the trials was randomized across each run and each participant, balanced across conditions. Prior to the beginning of the scanning session, participants trained on the task for 15 min outside the scanner bore, in a lying position with the same experimental setup on the scanner bed, until they were error-free and able to complete the movement execution within the $3 \mathrm{sec}$ between the go cue and closure of the PLATO spectacles.

\section{Experimental Conditions}

There were four experimental conditions, in a $2 \times 2$ experimental design, based on the cup, and hand orientations, instructed by the task. The combination of the cup and initial hand orientation, which were provided in the planning phase, determined affordance effects. The initial cup orientation was either upright or upside-down. A verbal instruction specified how participants should orient their hand grasp from the resting position on the 
pad after the beep. This instruction was either to orient their hand "straight" or "invert[ed]." This instruction determined the hand posture to adopt when grasping the cup at the start of the turn. Of note, the hand orientation adopted at the start of the turn also determined whether the end posture was comfortable or not. The use of different verbal instructions for the hand posture ("straight," meaning that participants had to grasp the cup with a supinated hand posture, vs. "invert," meaning that they had to grasp it with a pronated hand posture) was used to prevent confounds caused by a visual instruction, such as a marker on the object, which had been used in previous versions of this experiment, published elsewhere (Rounis et al., 2017). Indeed, a visual marker to indicate the starting hand posture to use on the cup would sometimes be in conflict with the object orientation and confound any hand-cup congruency activations in an fMRI experiment. As a result of this design, the end state comfort effect at the planning phase was influenced by the different verbal instruction cues. Although these activations are reported in the Results section (in terms of a main effect of hand orientation - "straight" vs. "invert"), this was not an effect of interest in our imaging results. The effects of end state comfort have been described elsewhere (Zimmermann, Toni, \& de Lange, 2013).

The combination of cup orientation and task instruction led to a congruency between the cup and hand orientation in two out of four conditions (Figure 2), which were our conditions of interest. These were the conditions when the cup was upright, and the hand instruction was "straight" or when the cup orientation was down and the hand instruction was "invert." Conversely, the two remaining conditions involved a hand orientation, specified by the

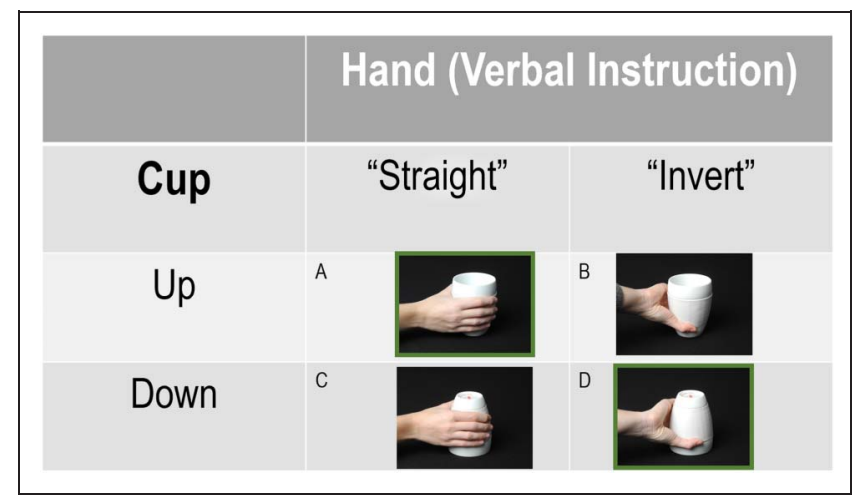

Figure 2. Factorial design. This was a $2 \times 2$ factorial design: The main factors of hand and cup orientation led to an interaction of "affordance" (when both were congruent, condition "A" being when the cup is upright and the hand approaching it is "straight" and condition " $\mathrm{D}$ " being when the cup is upside-down and the hand approaching it is "invert(ed)" in this case), highlighted with a green square. The remaining, nonafforded, conditions were "B" when the cup was up and the hand approaching it was inverted (note this led to a comfortable end posture after a turn) and "C" when the cup was oriented down and the hand orientation at the start was straight. Of note, the actual cup used in this task was purposely built with Perspex and cylindrical in shape so that its width at the top and bottom was the same, as in Figure 1. verbal cue, that was incongruent with the cup orientation, such that participants grasped the closed end of the cup. These included the conditions when the verbal cue was "straight" and the cup orientation was down, or else when the verbal instruction was "invert" and the cup orientation was upright. In both cases, the action performed after the go cue was to turn the cup from one orientation to the other. Figure 1 depicts the experimental setup and timings. The experimental task conditions are shown in Figure 2. A representative video of a task condition is also provided.

\section{Behavioral Analysis}

The behavioral responses relevant to the task, which are reported below, corresponded to the time interval recorded between the go cue and the hand releasing the home key (the 'reaction time,' RT), measured for each trial. This time interval is felt to represent movement planning (Wong, Haith, \& Krakauer, 2015) and corresponds to the time at which compatibility effects in response to handled objects have been observed previously (Pizzamiglio et al., 2020; Rounis et al., 2017; Masson, Bub, \& Breuer, 2011; Bub \& Masson, 2010). RTs for each participant in each condition were entered as our dependent variable in the behavioral analyses. The remaining times (namely, the time to reach and manipulate the object, and return to the home key, i.e., from cup lifting to be turned to cup being repositioned back on the cupholder to hand return to the home key) were not further analyzed behaviorally. However, these timings were taken into account and modeled separately from the initial parts of the movement, in the general linear model (GLM) imaging analysis.

Error trials were recorded by the experimenter who documented if the object manipulation was correctly performed in each trial, during the experiment. These included technical errors and behavioral errors (wrong grasp, action too slow, hesitation, hand posture adjusted during reaching, etc.). In addition, trials in which RTs were either above or below $2.5 \mathrm{SDs}$ of mean RT for each condition in each participant, or where participants took longer than 3 sec to complete the cup manipulation, were excluded as errors. Error trials were excluded from behavioral analyses and modeled separately in the GLM imaging analysis.

A repeated-measures ANOVA using RTs to investigate the effects of Cup and Hand Congruency was implemented using IBM SPSS Statistics 25 for Windows software (SPSS Inc.). As mentioned above, the effect of affordance is equivalent to an interaction effect between hand and cup orientations. The Type I error rate was set at $p<.05$ for the analyses reported here. Greenhouse-Geisser correction for degrees of freedom was used when the assumption of sphericity was not met.

\section{Image Acquisition}

MRI data were acquired on a Siemens 3 T Trio MRI scanner at the University of Oxford Centre for Clinical Magnetic 
Resonance Research. For purposes of coregistration with functional data, structural T1-weighted MRI images were acquired using the magnetization prepared rapid gradient echo sequence (repetition time $=2040 \mathrm{msec}$; echo time $=$ $4.7 \mathrm{msec}$; field of view $=174 \times 192 \mathrm{~mm}^{2}$; 192 slices; voxel size $=1 \times 1 \times 1 \mathrm{~mm}^{3}$ ). Functional images were acquired using an echo planar imaging sequence (repetition time $=$ $2230 \mathrm{msec}$; echo time $=30 \mathrm{msec}$; flip angle $=87^{\circ}$; isotropic voxels of $3 \mathrm{~mm}$, no slice gap; field of view $=192 \times 192 \mathrm{~mm}^{2}$; 37 slices; voxel size $=3 \times 3 \times 3 \mathrm{~mm}^{3}$ ).

\section{Imaging Data Preprocessing and Analyses}

\section{Preprocessing}

Functional imaging data were preprocessed and analyzed using SPM12 (www.fil.ion.ucl.ac.uk/spm). The first three volumes for each session were discarded to allow for MRI signal equilibration. The image time series were spatially realigned using rigid body transformation and a sinc-interpolation algorithm (Friston et al., 1994). The time series for each voxel was temporally realigned to the first slice of each image volume.

The anatomical image was coregistered with the mean functional image and then segmented. Deformation fields were obtained from the segmentation step, which were used to normalize the functional images to the Montreal Neurological Institute (MNI) standard space. Spatial smoothing was applied to the normalized functional images with an 8-mm FWHM Gaussian kernel.

\section{GLM}

For each participant, the fMRI time series were concatenated from 10 runs for GLM analysis (Friston et al., 1994). Singlesubject models consisted of regressors separately describing the viewing phase (glasses opening, leading to visualization of the cup), planning (indexed by verbal instruction cue), go cue (corresponding to the auditory beep indicating action initiation), movement completion phase (from reaching to turn the cup to the return of the hand to the home key), PLATO closure phases as well as the errors for all conditions. The planning phase was split into distinct parametric modulators for grasping movements according to cup orientation (upright or down), hand orientation ("straight" or "inverted"), and affordance ("afforded" being when the hand and cup orientation were congruent, "not afforded" when they were not). The viewing phase regressor was time-locked to the opening of the PLATO glasses, with a duration of zero. Each of the three planning phase parametric modulators were time-locked to the onset of the verbal cue ("straight" or invert), with a duration of zero. We conjectured that the neural correlates of cup and hand congruency or affordance effects would occur during the planning phase and that these would correspond to the RT changes identified behaviorally (Pizzamiglio et al., 2020;
Wong et al., 2015; Rounis et al., 2007). Moreover, affordance effects identified at the planning phase would not be confounded by movement-related activity changes during motor execution. The go cue was modeled as a separate single regressor, with a duration of zero. The movement completion phase was time-locked to the onset of the go cue and duration from hand lift-off to return to the home key after turning the cup in each trial. There was a regressor time-locked to the closure of the PLATO glasses, and a duration of zero. The final regressor was for error trials, with the onset being the opening of the glasses and duration being the closing of the PLATO glasses for each error trial.

These regressors were convolved with a canonical hemodynamic response function without derivative terms. Head motion was accounted for by adding the six head motion parameters as additional "nuisance" regressors (Friston et al., 1994). Regressors that modeled the onset and duration for each run were added to account for brain activity differences across runs. Slow signal drifts were removed by using a 1/128-Hz high-pass filter. Serial correlations were accounted for with an autoregressive AR (1) model.

In order to obtain the activity maps for the planning phase, the subject-level contrast images for each phase were subjected to a group-level random effects analysis. One-sample $t$ tests were used to compare between conditions of interest. We assessed the effects of the hand, cup, and affordance by using subject-level contrast images for the parametric modulators in group-level one-sample $t$ tests. We applied cluster-wise FWE corrected for multiple comparisons at $p<.05$, with a height cluster-forming threshold of $p<.001$ across the whole brain.

Changes in connectivity within the network engaged in this task were assessed using psycho-physiological interactions (PPI), a method first described by Friston et al. (1997). The PPI analysis explains responses in one cortical area in terms of an interaction between activity in another cortical area (index area) and the influence of an experimental condition. We used this to test the hypothesis that congruency between the hand and cup orientations specified during the task instruction modulated connectivity between the left dorsal premotor (L PMd), involved in motor planning, with other areas involved in the planning phase of this cup manipulation task. This hypothesis is based on previous literature that reports this area to be involved in motor planning for object use (Gallivan, McLean, Valyear, et al., 2013; Gallivan et al., 2011; Grèzes et al., 2003) and more specifically in representing affordances (Cisek \& Kalaska, 2005, 2010; Cisek, 2007). Three variables were created for this PPI analysis in a GLM: a physiological variable for the BOLD signal in the seed region, a psychological variable corresponding to the parametric modulator for the congruency effect at the planning phase, and a PPI variable. The seed was selected based on the specific effects of congruency in that phase and a priori hypothesis for a role of PMd areas 


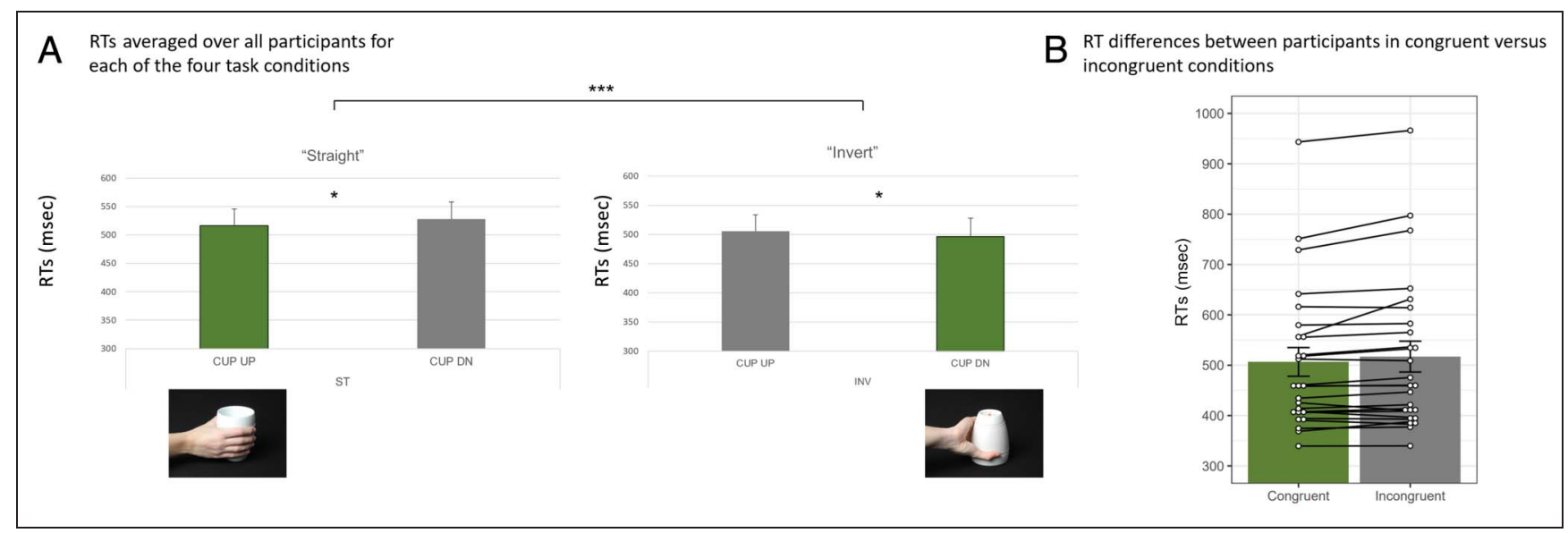

Figure 3. Behavioral results. (A) The RTs represented the time at which participants lifted their hand off the home key to initiate the action. The left panel reports RTs for actions that were initiated with a "straight" (supinated) hand posture when reaching to turn the cup. The right reports RTs for actions that were initiated with an "inverted" (pronated) hand orientation. In both cases, we identified effects of congruency between the hand and cup orientations at this time, indicating that RTs were shorter for trials in which the hand and cup orientations were congruent than for ones in which they were not $(* p=.011$ - effect of "affordance"); moreover, they were shorter when planning actions starting with an inverted grasp and ending comfortably, compared to ones that started with a "straight" hand orientation. (B) This figure depicts the same results as above, with individual data points averaged across end state comfort effects for the congruent (in green) versus incongruent (in gray) conditions.

in action selection (Cisek \& Kalaska, 2005; Arbib, Billard, Iacoboni, \& Oztop, 2000; Grafton, Fagg, \& Arbib, 1998). We wanted to investigate changes in connectivity with L PMd underlying the congruency effects. For each participant, we located the peak voxel within the cluster identified by the group-level congruency contrast for the planning phase and built a 6-mm sphere VOI centered at the peak voxel. We extracted a BOLD signal from each VOI, adjusted for the effects of the hand, cup, and congruency at the planning phase. In order to derive brain interactions at the neuronal level, the BOLD signal was deconvolved through hemodynamic function onto the neural level before creating the interaction variable.
These three PPI variables were fed into a GLM analysis, together with six head motion estimates as variables of no interest. Subject-level contrast images for the interaction variable were entered in group-level one-sample $t$ tests.

The anatomical localization for significant regions was identified based on the SPM anatomy toolbox (Eickhoff et al., 2005), supplemented by the multimodal parcellation of human cerebral cortex provided by the Human Connectome Project (Andreas, 2016; Glasser et al., 2016) and direct anatomical interpretation of our results based on Petrides' Atlas of the Morphology of the Human Cerebral Cortex on the MNI Brain (Petrides, 2019). The

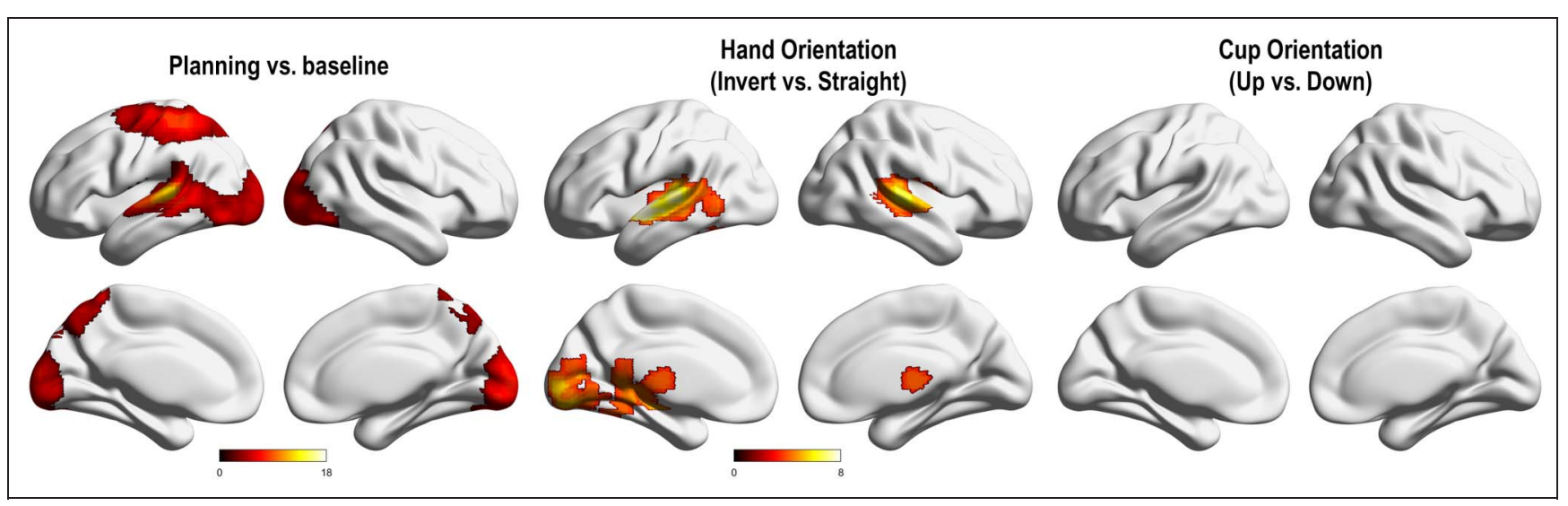

Figure 4. Imaging results at the planning phase. This figure depicts activation maps in planning versus baseline (the activation reported in Table 1) on the left, effect of hand orientation in the middle-depicting the conditions when the hand instruction was straight (leading to uncomfortable end state) versus the ones in which it was "invert" (leading to comfortable end state) - and effects of cup orientation on the right, with no significant activation for that condition. The results are shown at $\mathrm{FWE}<0.05$ whole-brain, cluster-wise correction. The activation maps have been overlayed on a rendered structural T1 MRI map in MNI space from BrainNet viewer (www.nitrc.org/projects/bnv/), depicting activations in lateral (top) and medial (bottom) aspects of the left and right hemispheres, respectively. The color bar indicates $t$ values for activations in the areas of interest. 
figures were created using the Brain Net viewer, www.nitrc .org/projects/bnv/ (Xia, Wang, \& He, 2013).

\section{RESULTS}

\section{Behavioral Results}

Error trials including behavioral errors (1.85\%) and technical errors (2.35\%) were excluded from RT analysis.
Outlier RTs were removed based on 2.5 SDs from the mean value for each condition and trials that were completed beyond 3 sec for each subject (2.52\% excluded). Hence, the total number of trials (403) excluded were $6.72 \%$ of all trials. Error trials were not analyzed any further.

A repeated-measures ANOVA for the RT data (Figure 3 ) revealed a significant main effect of Hand Posture, $F(1,24)=$

Table 1. Brain Regions Associated with Increased Activity during the Planning Phase (at Time of Verbal Cue Instruction; Cluster-wise pFWE $<.05)$

\begin{tabular}{|c|c|c|c|c|c|c|c|}
\hline Anatomical Region & Hemisphere & $x$ & $y$ & $z$ & $t$ Value & Voxel Count & $\begin{array}{l}\text { Cluster-level } p \\
\text { FWE-corrected }\end{array}$ \\
\hline Middle temporal gyrus & Left & -60 & -34 & 8 & 12.40 & 1514 & $<.001$ \\
\hline \multirow[t]{2}{*}{ Superior temporal gyrus } & \multirow[t]{2}{*}{ Left } & -57 & -16 & 5 & 8.80 & & \\
\hline & & -60 & 2 & -7 & 4.11 & & \\
\hline Cuneus (V2, V3d) & Left & -3 & -97 & 14 & 7.29 & & \\
\hline \multirow[t]{3}{*}{ Calcarine gyrus (V1, V2) } & Left & 0 & -88 & 2 & 6.22 & & \\
\hline & \multirow[t]{2}{*}{ Right } & 6 & -97 & 5 & 7.41 & & \\
\hline & & 3 & -88 & -7 & 7.28 & & \\
\hline \multirow{4}{*}{$\begin{array}{l}\text { Inferior occipital gyrus } \\
\text { (lateral occipito-temporal complex) }\end{array}$} & \multirow[t]{2}{*}{ Left } & -51 & -73 & -4 & 6.33 & & \\
\hline & & -33 & -91 & -10 & 5.88 & & \\
\hline & \multirow[t]{2}{*}{ Right } & 36 & -82 & -13 & 6.21 & & \\
\hline & & 30 & -91 & -10 & 6.64 & & \\
\hline Inferior occipitotemporal/fusiform gyrus & Right & 48 & -70 & -13 & 5.10 & & \\
\hline \multirow[t]{3}{*}{ Middle occipital gyrus (V3d/V3A) } & Left & -21 & -97 & 11 & 5.51 & & \\
\hline & Right & 30 & -88 & 20 & 3.78 & & \\
\hline & Right & 36 & -91 & -1 & 6.37 & & \\
\hline \multirow[t]{2}{*}{ Superior occipital gyrus (V3d/V3A) } & Left & -12 & -97 & 14 & 6.25 & & \\
\hline & Right & 24 & -94 & 11 & 5.65 & & \\
\hline Cerebellum & Right & 24 & -73 & -19 & & & \\
\hline \multirow[t]{3}{*}{ Superior parietal lobe (Area 2, 5L, 7PC) } & \multirow[t]{3}{*}{ Left } & -33 & -43 & 59 & 8.37 & 921 & $<.001$ \\
\hline & & -24 & -55 & 65 & 5.89 & & \\
\hline & & -15 & -73 & 53 & 4.64 & & \\
\hline $\begin{array}{l}\text { Postcentral gyrus (Area 4p, 4a, 3b) - } \\
\text { primary motor area (M1) }\end{array}$ & Left & -36 & -34 & 59 & 8.28 & & \\
\hline \multirow[t]{3}{*}{ Precentral gyrus, PMd cortex } & \multirow[t]{3}{*}{ Left } & -33 & -19 & 68 & 6.64 & & \\
\hline & & -36 & -7 & 65 & 6.25 & & \\
\hline & & -24 & -7 & 65 & 4.91 & & \\
\hline \multirow[t]{5}{*}{ Precuneus/superior parietal lobule $(7 \mathrm{P} / 7 \mathrm{~A})$} & \multirow[t]{3}{*}{ Left } & -3 & -52 & 68 & 6.97 & & \\
\hline & & -6 & -79 & 47 & 5.93 & & \\
\hline & & -3 & -64 & 59 & 5.45 & & \\
\hline & \multirow[t]{2}{*}{ Right } & 9 & -70 & 59 & 4.55 & & \\
\hline & & 9 & -76 & 53 & 4.22 & & \\
\hline
\end{tabular}


$46.5, p=4.7 \mathrm{E}-07$, partial eta ${ }^{2}=.66, M S E=228.733$, with "inverted" grasp being initiated with shorter RTs than "straight" grasps (501.48 vs. $522.11 \mathrm{msec}$ ); no main effect of Cup Orientation, $F(1,24)=0.124, p=.728$, partial eta $^{2}=.005, M S E=295.56$; and a significant interaction between the two, $F(1,24)=7.551, p=.011$, partial eta ${ }^{2}=$ $.24, M S E=367.21$, with shorter RTs for the conditions in which hand and cup orientations were congruent ("afforded" trials - Figure 2) than ones in which they were not (506.53 vs. $517.01 \mathrm{msec})$.

Table 2. The Effects of Hand Orientation (Invert $>$ Straight) during the Planning Phase (Cluster-wise, $p$ FWE $<.05$ )

\begin{tabular}{|c|c|c|c|c|c|c|c|}
\hline Anatomical Region & Hemisphere & $x$ & $y$ & $z$ & $T$ & Voxel Count & $\begin{array}{l}\text { Cluster-level p } \\
\text { FWE-corrected }\end{array}$ \\
\hline \multirow{4}{*}{$\begin{array}{l}\text { Superior temporal gyrus } \\
\text { (primary and secondary auditory areas, } \\
\text { including cluster in visual BA 22) }\end{array}$} & \multirow[t]{4}{*}{ Left } & -51 & -13 & 2 & 8.13 & \multirow[t]{16}{*}{932} & \multirow[t]{16}{*}{$<.001$} \\
\hline & & -60 & -28 & 5 & 7.09 & & \\
\hline & & -42 & -31 & 11 & 5.58 & & \\
\hline & & -51 & -37 & 14 & 4.76 & & \\
\hline \multirow[t]{2}{*}{ Middle temporal gyrus } & & -39 & -55 & 11 & 3.99 & & \\
\hline & & -48 & -55 & -1 & 4.39 & & \\
\hline Inferior temporal gyrus & & -42 & -37 & -16 & 4.70 & & \\
\hline Fusiform gyrus & & -36 & -43 & -10 & 4.59 & & \\
\hline TE3/middle temporal gyrus, STSv & & -60 & -28 & 5 & 7.09 & & \\
\hline Hippocampus & & -36 & -22 & -10 & 5.25 & & \\
\hline Parahippocampal gyrus & & -15 & -37 & -7 & 4.74 & & \\
\hline Thalamus & & -18 & -31 & -1 & 4.15 & & \\
\hline Insula & & -30 & -28 & 20 & 3.87 & & \\
\hline Post cingulate gyrus & & -6 & -43 & 17 & 3.79 & & \\
\hline Middle occipital gyrus & & -39 & -61 & 5 & 3.65 & & \\
\hline Calcarine sulcus & & -12 & -46 & 5 & 4.57 & & \\
\hline $\begin{array}{l}\text { Superior temporal gyrus } \\
\text { (primary and secondary auditory areas, } \\
\text { bordering inferior parietal lobule) }\end{array}$ & \multirow[t]{7}{*}{ Right } & 60 & -25 & 8 & 6.51 & \multirow[t]{7}{*}{451} & \multirow[t]{7}{*}{$<.001$} \\
\hline Auditory 5 complex & & 66 & -22 & -1 & 5.96 & & \\
\hline Medial belt complex (MBelt) & & 54 & -16 & 5 & 5.65 & & \\
\hline ParaBelt complex (PBelt) & & 60 & -10 & 5 & 5.61 & & \\
\hline \multirow[t]{2}{*}{ Superior temporal gyrus } & & 42 & -31 & 11 & 5.18 & & \\
\hline & & 63 & -40 & 11 & 4.70 & & \\
\hline Middle temporal gyrus & & 45 & -34 & -1 & 5.11 & & \\
\hline $\begin{array}{l}\text { Lingual gyrus/posterior inferotemporal } \\
\text { (BA 18) }\end{array}$ & \multirow[t]{3}{*}{ Left } & -15 & -85 & -7 & 5.75 & \multirow[t]{8}{*}{231} & \multirow[t]{8}{*}{.024} \\
\hline \multirow[t]{2}{*}{ Lingual gyrus } & & -12 & -67 & -1 & 4.10 & & \\
\hline & & -15 & -58 & -10 & 3.75 & & \\
\hline Superior occipital gyrus & & -12 & -91 & 2 & 5.42 & & \\
\hline Calcarine sulcus & & -15 & -82 & 8 & 4.83 & & \\
\hline Fusiform gyrus & & -27 & -73 & -4 & 4.31 & & \\
\hline Cuneus & & -9 & -82 & 17 & 4.00 & & \\
\hline Cerebellum & & -6 & -67 & -19 & 3.86 & & \\
\hline
\end{tabular}


Table 3. The Effects of Congruency (Incongruent $>$ Congruent) during the Planning Phase (Cluster-wise, $p \mathrm{FWE}<.05$ )

\begin{tabular}{|c|c|c|c|c|c|c|c|}
\hline Anatomical Region & Hemisphere & $x$ & $y$ & $z$ & $T$ & Voxel Count & $\begin{array}{l}\text { Cluster-level p } \\
\text { FWE-corrected }\end{array}$ \\
\hline \multirow[t]{4}{*}{ Premotor area (superior frontal gyrus) } & \multirow[t]{4}{*}{ Right } & 21 & 2 & 56 & 5.20 & \multirow[t]{4}{*}{88} & \multirow[t]{4}{*}{.015} \\
\hline & & 24 & -4 & 62 & 4.93 & & \\
\hline & & 21 & -10 & 68 & 4.26 & & \\
\hline & & 24 & 8 & 65 & 3.70 & & \\
\hline \multirow[t]{3}{*}{ Premotor (superior frontal/precentral gyrus) } & \multirow[t]{3}{*}{ Left } & -24 & -7 & 59 & 4.40 & \multirow[t]{3}{*}{89} & \multirow[t]{3}{*}{.015} \\
\hline & & -15 & -4 & 71 & 4.23 & & \\
\hline & & -33 & 2 & 59 & 3.71 & & \\
\hline
\end{tabular}

\section{Imaging Results}

A random effects analysis investigating effects of our task conditions at the group level was performed. The overall activations at the planning phase, relative to the implicit baseline of intertrial intervals, are reported in Figure 4 (left) and in Table 1 . The results reported here were whole-brain corrected at FWE $p<.05$, cluster-wise.

A wide network of areas was activated, predominantly within the precentral, postcentral gyri, superior parietal lobule, intraparietal sulcus of the left hemisphere, but also including bilateral activations in the occipital and temporal areas. The left superior temporal activation included auditory and visual subdivisions (notably BA 22) and adjacent left middle temporal gyrus (Figure 4, Table 1).

The main effect of Hand Orientation (which was represented by the initial hand orientation being "inverted" for a comfortable end-state vs. "straight" for an uncomfortable one) activated bilateral superior temporal gyri (including auditory areas, corresponding to the auditory cue instruction, and visual subdivisions BA 22), occipital cortices including inferotemporal and lateral occipito-temporal areas and thalamus (Table 2, Figure 4, middle). Activity in these areas was greater when turning a cup with an inverted (pronated) grasp, to end in a comfortable, supinated, hand posture, compared to turning it with a straight (supinated) grasp to end in an uncomfortable, pronated posture.

There were no significant activations identified for the main effect of Cup Orientation at the planning phase (Figure 4, right).

The interaction between the Cup and Hand Orientations, namely, the effect of affordance in the planning phase, revealed significant activations in the $\mathrm{L}$ PMd and right dorsal premotor (R PMd) cortices (L PMd main cluster $x=-24, y=-7, z=59, T=4.40$, cluster size $=89$ voxels, $p \mathrm{FWE}=.015$; $\mathrm{R}$ PMd main cluster $x=21, y=2, z=56, T=$ 5.20 , cluster size $=88$ voxels, $p \mathrm{FWE}=.015)$. The sign of this congruency effect indicated greater activation for trials that were not afforded, that is, where hand and cup orientations were incongruent (Table 3, Figure 5).
We then applied PPI analyses to test the hypothesis that congruency between the hand and cup orientations specified during the task instruction modulated connectivity between the PMd areas identified as mediating the affordance effect in this and previous studies (Cisek \& Kalaska, 2005, 2010; Cisek, 2007; Grèzes et al., 2003) and other areas involved in the planning object manipulation within dorsal and ventral stream (Sakreida et al., 2016; Gallivan, McLean, Valyear, et al., 2013; Gallivan et al., 2011; Grèzes et al., 2003; Grafton et al., 1998).

The L PMd ( $x=-24, y=-7, z=59$ ) involved during movement planning was chosen as the seed area for our PPI analysis, looking for changes in coupling between this area and areas of the dorsal and ventral visuomotor networks based on hand-object congruency, during the planning phase. This PPI revealed one area in which coupling was significantly increased in conditions that

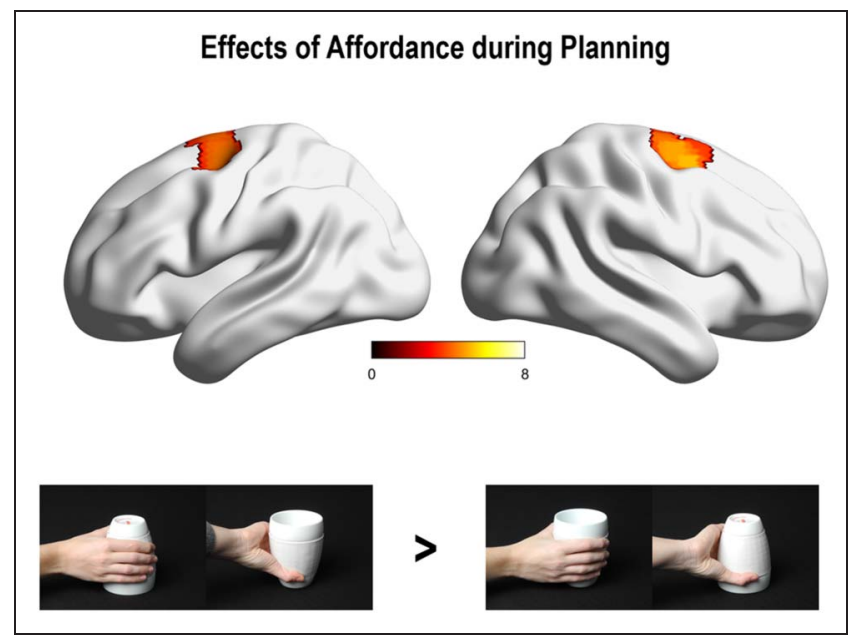

Figure 5. Effects of hand-cup congruency on task-related activity. Activation map for the effect of affordance at the planning phase. The results are shown at $p \mathrm{FWE}<.05$ cluster-wise correction. There was significantly increased activity in the L PMd and R PMd cortices in conditions in which the hand and cup orientation were incongruent during the planning phase. 


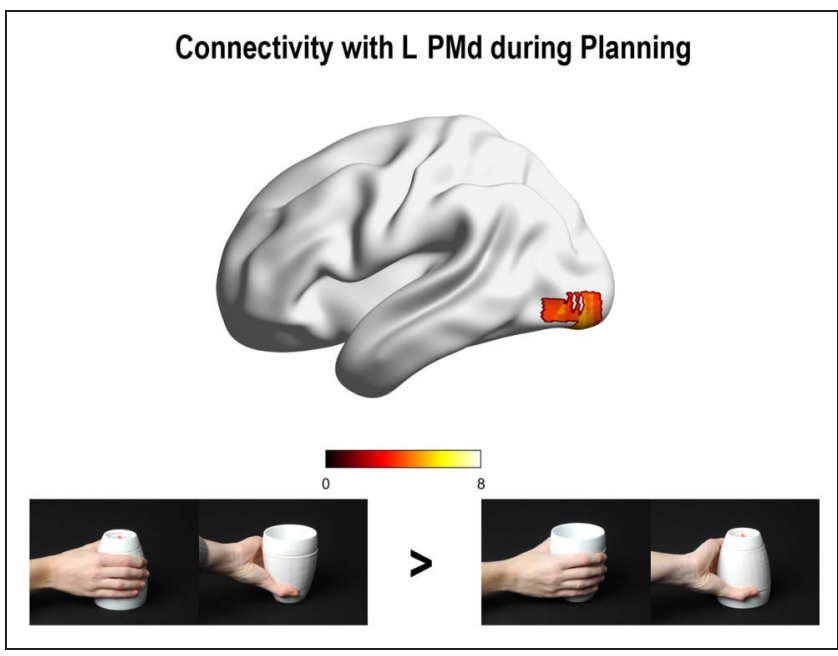

Figure 6. L PMd PPI results. Activation map identifying areas of increased connectivity with the L PMd modulated by affordances in the planning phase. The areas included formed part of the left inferotemporal and lateral occipital areas forming the LOTC. As in the previous figure, these activation maps have been overlayed on a rendered structural T1 MRI map in MNI space from BrainNet viewer and the color bar indicates $t$ values for activations in the areas of interest.

were incongruent within the left lateral occipito-temporal Cortex (LOTC; $x=-30, y=-85, z=-10, T=5.29$, and $x=-39, y=-76, z=-4, T=4.9$, cluster of 71 voxels, $p \mathrm{FWE}=.028)$. Coupling between the L PMd and LOTC area was increased when the hand and cup orientations were incongruent (Figure 6). Of note, a PPI investigating affordance-related connectivity changes with the $\mathrm{R}$ PMd ( $x=21, y=2, z=56)$ revealed no significant results.

\section{DISCUSSION}

In this study, we investigated the influence of cup orientation on goal-directed actions when planning to turn it. To our knowledge, this is the first study pitting habitual versus goal-directed responses elicited by hand-object interactions during real object manipulation in a functional imaging environment. Participants performed a delayed-movement task in which they reached and turned a cup when it was oriented either upright or upside-down. They were instructed to use a hand orientation to turn the cup that was either congruent or incongruent with the object orientation. As in previous studies (Pizzamiglio et al., 2020; Rounis et al., 2017), we identified a behavioral effect of congruency (an "affordance" effect). Movements where the hand and cup orientations were congruent were initiated faster than ones in which they were not (Hardwick et al., 2019; Rounis et al., 2017).

Planning to turn a cup in this task affected activity in areas involved in object manipulation (Gallivan, McLean, Valyear, et al., 2013; Gallivan et al., 2011; Grol et al., 2007; Mahon et al., 2007; Daprati \& Sirigu, 2006; Grèzes et al., 2003; Goodale \& Milner, 1992). In addition, there was increased activity in bilateral PMd when planning trials in which the hand and the cup orientation were incongruent, compared to ones where they were congruent (these were trial conditions that were afforded, i.e., which led to habitual hand-object interactions). The L PMd's connectivity with the left LOTC was increased in those same trial conditions. We discuss these imaging and behavioral results depicting habitual versus goal-directed planning in the context of previous literature investigating motor control and hand posture representations and propose that they reflect processes underlying selection of hand postures for a task.

\section{The Neural Correlates of Habitual Responses Elicited by Affordances on Posture Representations in the Brain}

In this study, planning object-related manipulations in which object and hand orientations were incongruent was associated with increased activity in bilateral PMd in the dorsal stream (Wolpe, Hezemans, \& Rowe, 2020; Nachev, Kennard, \& Husain, 2008; Rizzolatti \& Matelli, 2003). PPI analysis investigating areas of connectivity changes relating to this congruency effect, revealed increased functional connectivity between L PMd and the left LOTC, located in the ventral stream, in incongruent (i.e., "nonafforded") task conditions.

The PMd plays an important role in action selection and is likely involved in triggering competing action representations elicited by affordances, as demonstrated both in human neuroimaging and nonhuman primate neurophysiological studies on which models of reach and grasp behavior are modeled within dorsal stream networks (Cisek, 2007; Grafton et al., 1998). Neurophysiological studies in nonhuman primates have shown that L PMd activity increases during motor preparation when planning competing reach movements (Cisek, 2005, 2007; Cisek \& Kalaska, 2005). Applying repetitive transcranial magnetic stimulation over this area leads to slower motor performance when the instructed response is not congruent with the visual stimulus (Rushworth et al., 2001; Praamstra, Kleine, \& Schnitzler, 1999).

In addition to enhanced activity in PMd areas, planning incongruent (goal-directed) hand-object actions was associated with functional connectivity changes between the L PMd and ventral stream area LOTC. The inferotemporal area and adjacent inferior occipital lobe form the ventral stream pathway representing objects (van Elk, van Schie, \& Bekkering, 2014; Mahon et al., 2007; Chao, Haxby, \& Martin, 1999; Kanwisher, Stanley, \& Harris, 1999; Dolan et al., 1997). This area has been shown to incorporate knowledge of body and hand posture for tool use (Bracci, Caramazza, \& Peelen, 2018; Zimmermann, Mars, de Lange, Toni, \& Verhagen, 2018; Bracci \& Peelen, 2013; Zimmermann et al., 2013; Bracci, Ietswaart, Peelen, \& Cavina-Pratesi, 2010; Rice, Valyear, Goodale, Milner, \& 
Culham, 2007; Valyear et al., 2007). It responds to movement-invariant hand postures and to motor-element properties of objects (Bracci et al., 2010, 2018; Wurm, Caramazza, \& Lingnau, 2017; Lingnau \& Downing, 2015; Bracci \& Peelen, 2013) and is functionally connected with dorsal stream areas (Zimmermann et al., 2018).

Previous functional imaging studies involving objectdirected actions in the scanner have also identified taskrelated BOLD activations within subdivisions of dorsal and ventral visual stream areas (Sakreida et al., 2016) dependent of the type of action performed (e.g., grip) and properties of the object (e.g., large or small; Sakreida et al., 2016; Gallivan, McLean, Valyear, et al., 2013; Gallivan et al., 2011; Grol et al., 2007; Mahon et al., 2007; Valyear et al., 2007). Our PPI interaction results in which there is functional interactions between "dorsodorsal" L PMd and ventral stream area LOTC in trials where hand posture and object orientation were incongruent demonstrate an integration between dorsal and ventral stream areas when preparing goal-directed object manipulations (van Polanen \& Davare, 2015). This result suggests that, whereas affordance may elicit known hand posture-object interactions during habitual actions, goaldirected actions likely require the elicitation of new hand posture and object combinations for its manipulation. This engages LOTC, an area involved in representing these complex object and posture relationships in the ventral stream, which involve higher-order perceptual-semantic processes (Holler, Fabbri, \& Snow, 2020; Till, Masson, Bub, \& Driessen, 2014; Creem \& Proffitt, 2001).

\section{Contextual Factors Determining Affordance Effects and Their Influence on Imaging Results}

A variety of perceptual tasks have shown that visual properties of objects can give rise to action representations (Humphreys et al., 2010; Mahon et al., 2007; Grèzes \& Decety, 2002; Chao \& Martin, 2000). In a previous imaging study, the neural correlates of affordances were investigated using Tucker and Ellis' (2001) paradigm (Grèzes et al., 2003). Participants in that task had to categorize objects as either natural or man-made by making a precision grip for one category and a power grip for another, in a counterbalanced order. They identified affordance effects to be associated with increased activations involving anterior intraparietal area, PMd, and inferior frontal cortex. The identification of L PMd, known to for its role in action selection when reaching, corroborates our results. The anterior intraparietal and inferior frontal areas are involved in grip selection (Fagg \& Arbib, 1998) and are also known to be more active in precision, compared to power grip (Grol et al., 2007), which would explain why these additional areas were identified in that task.

Other notable differences between the Grèzes et al. (2003) study and ours involved the stimuli used for eliciting affordance effects. Their study used 2-D images and asked participants to categorize objects. Previous studies have reported stronger affordance effects with real objects (Gomez et al., 2018; Snow et al., 2011) compared to 2-D images of objects (Bub et al., 2018; Bub \& Masson, 2010). In a recent study, healthy participants were asked to categorize real objects and 2-D images of objects. Comparing categorizations between the two identified that they used both factors relating conceptual and physical characteristics to categorize real images, whereas 2-D images were mostly categorized on the basis of conceptual characteristics alone (Holler et al., 2020).

Conversely, our study involved manipulating a real object (a cup). Although our task did not involve any overt semantic categorization (Humphreys et al., 2010; Daprati \& Sirigu, 2006), evidence from tasks in which participants interact with real objects would suggest that some form of semantic control, perhaps involving higher-order perceptual hand posture-object categorization, may occur covertly (Holler et al., 2020; Creem \& Proffitt, 2001), which would be supported with the identification of LOTC in our PPI results.

The differences between the Grèzes et al. (2003) and our results corroborate the importance of contextual factors, when interpreting affordance effects reported in the literature. Several experiments have challenged and failed to replicate traditional findings attributed to affordances of speeded keypress responses to 2-D pictures (Bub et al., 2018, 2021; Tucker \& Ellis, 1998). These results are often not replicated if responses involve keypress within the same hand, rather than reach-and-grasp actions. They may even show a paradoxical reversal affordance depending on the characteristics of the object depicted in the 2-D image, such as its elongation on a 2-D plane, and whether the whole object (e.g., including base and handle in a frying pan) is fixated upon. Another issue, discussed in the Methods section above, is that some experimental designs in which handles are pointing left or right may confound motor and visuospatial attention (Rounis et al., 2007; Rushworth et al., 1997, 2001) leading to debates about whether affordances relate to the latter (Bub et al., 2018; Wilf et al., 2013). For these reasons, we selected a task involving manipulation of a real object in the scanner (Holler et al., 2020; Gomez et al., 2018; Snow et al., 2011), in which the congruency between object orientation and participants' real reach and grasp responses were centrally located (Bub \& Masson, 2010; Rounis et al., 2007).

\section{Affordances or Competition between Habitual and Goal-directed Actions}

This fMRI study replicated behavioral results we previously reported using the same task in healthy volunteers and in stroke patients (Pizzamiglio et al., 2020; Rounis et al., 2017). Motor initiation was faster in trials in which the hand and cup orientation were congruent. RTs represent the time when a decision about what action to implement and how to execute it takes place (Wong et al., 2015). 
Several studies have reported compatibility effects at that time (Hardwick et al., 2019; Rounis et al., 2017; Bub \& Masson, 2010; Grèzes et al., 2003; Tucker \& Ellis, 1998). In addition to RT effects, affordances affect kinematic measures during object-directed actions in human studies (Rounis, van Polanen, \& Davare, 2018; Gentilucci, 2002). The longer RTs and kinematic changes we and others have observed in incompatible trials suggest a competition between movement representations that are habitual, compared to the ones demanded by the task (Hardwick et al., 2019; Rounis et al., 2007, 2018; Herbort \& Butz, 2011; Rushworth et al., 1997). A similar observation was made in a study comparing grasp strategies to hammer a peg in young infants versus adults (Ossmy et al., 2020). They showed "model-free" behavior in infants who were more likely to engage an overhand grasp to pick the hammer with their nondominant, requiring them a two-step process to pass it onto their dominant hand. Conversely, adults grasped the hammer with an underhand grasp using their dominant hand, which was more efficient but took longer to plan and perceive, suggesting development involves a process of transition from habitual "model-free" to goal-directed "model-based" behavior (Drummond \& Niv, 2020; Dolan \& Dayan, 2013; Balleine \& Dickinson, 1998).

In a similar vein, the elicitation of movement representations by objects is of fundamental importance in understanding higher-order motor deficits in patient populations. There are several examples, in the neuropsychology literature, in which habitual and goal-directed systems may compete for control of action selection (Riddoch et al., 1998; Shallice, Burgess, Schon, \& Baxter, 1989). A recent study in which stroke patients with and without apraxia performed the same cup manipulation task as in this study identified that apraxic patients were unable to complete turn actions in which the cup and the hand orientations were incongruent. They favored habitual actions in which they grasped the cup from the open end in each trial (Pizzamiglio et al., 2020), supporting the hypothesis that patients with limb apraxia have deficits in exerting cognitive control over competing movement plans elicited by affordances (Rounis \& Humphreys, 2015). Other studies have shown that these patients demonstrate an overreliance on familiar (habitual) movements elicited by object affordances, at the expense of goaldirected actions (Pizzamiglio et al., 2020; Watson \& Buxbaum, 2015; Lee, Mirman, \& Buxbaum, 2014). Our imaging results might help explain the neural mechanisms underlying these patients' deficits, which are reported to involve both dorsal and ventral stream networks (Binkofski \& Buxbaum, 2013). Apraxic patients' impairments in completing goal-directed actions in this task may arise in one of two ways. One possible mechanism could be that lesions affecting action selection in PMd cause an inability to signal competing actions (habitual vs. goal directed). Alternatively, patients may have a deficit in integrating alternative posture representations in incongruent trials from lesions in LOTC. Further research would be required to test these alternative hypotheses.

Taken together, we identified a network of areas involved in representing object-directed actions in this cup manipulation task. Contextual factors led to a competition between habitual actions elicited by affordances and goaldirected actions during planning. This was associated with increased activity in PMd and increased connectivity of this area with LOTC when planning the latter. This process of competition between goal-directed and habitual actions may be impaired in stroke patients, leading to a deficit known as limb apraxia. Based on these and previous results, we hypothesize the disorder to relate either to an inability to represent alternative goal-directed hand postures in LOTC or to a failure in action selection signaled by L PMd.

\section{Acknowledgments}

We would like to thank the participants who took part in the study. This study was supported by personal grants to Dr. E. Rounis from the British Medical Association (Helen Lawson grant), Academy of Medical Sciences, and The Oxford Charitable Trust; and a Wellcome Trust Site Award to the Wellcome Centre for Human Neuroimaging. We would like to thank Daniel Voyce, John Prentice from the MRC Oxford Institute of Radiation Oncology, Gloria Pizzamiglio, Steven Knight, and Professor R. Passingham for their help and advice with this study.

Reprint requests should be sent to Elisabeth Rounis, Chelsea and Westminster NHS Foundation Trust, West Middlesex University Hospital, 23 Twickenham Road, Isleworth TW7 6AF, UK, or via e-mail: e.rounis@nhs.net.

\section{Author Contributions}

Zuo Zhang: Formal analysis; Investigation; Methodology; Visualization; Writing_-original draft; Writing_review \& editing. Peter Zeidman: Formal analysis; Methodology; Resources; Software; Supervision; Writing_review \& editing. Natalie Nelissen: Methodology; Resources; Software; Writing_review \& editing. Nicola Filippini: Data curation; Project administration; Validation; Writing-review \& editing. Jörn Diedrichsen: Conceptualization; Formal analysis; Investigation; Methodology; Validation; Writingreview \& editing. Stefania Bracci: Methodology; Supervision; Visualization; Writing — review \& editing. Karl Friston: Formal analysis; Funding acquisition; Software; Supervision; Validation. Elisabeth Rounis: Conceptualization; Formal analysis; Funding acquisition; Investigation; Methodology; Project administration; Resources; Supervision; Visualization; Writing_original draft; Writingreview \& editing.

\section{Funding Information}

Elisabeth Rounis, Oxford University Hospitals NHS Trust (https:/dx.doi.org/10.13039/501100006149), grant number: AH2016/1227. Karl Friston and Peter Zeidman, Wellcome Trust (https://dx.doi.org/10.13039/100004440), grant number: Site Award to Wellcome Centre for Human Neuroimaging. 


\section{Diversity in Citation Practices}

A retrospective analysis of the citations in every article published in this journal from 2010 to 2020 has revealed a persistent pattern of gender imbalance: Although the proportions of authorship teams (categorized by estimated gender identification of first author/last author) publishing in the Journal of Cognitive Neuroscience (JoCN) during this period were $\mathrm{M}(\mathrm{an}) / \mathrm{M}=.408, \mathrm{~W}($ oman $) / \mathrm{M}=.335$, $\mathrm{M} / \mathrm{W}=.108$, and $\mathrm{W} / \mathrm{W}=.149$, the comparable proportions for the articles that these authorship teams cited were $\mathrm{M} / \mathrm{M}=.579, \mathrm{~W} / \mathrm{M}=.243, \mathrm{M} / \mathrm{W}=.102$, and $\mathrm{W} / \mathrm{W}=.076$ (Fulvio et al., JoCN, 33:1, pp. 3-7). Consequently, JoCN encourages all authors to consider gender balance explicitly when selecting which articles to cite and gives them the opportunity to report their article's gender citation balance. The authors of this article report its proportions of citations by gender category to be as follows: $\mathrm{M} / \mathrm{M}=.583, \mathrm{~W} / \mathrm{M}=$ $.217, \mathrm{M} / \mathrm{W}=.083$, and $\mathrm{W} / \mathrm{W}=.117$.

\section{REFERENCES}

Andreas, H. (2016). HCP-MMP1.0 projected on MNI2009a GM (volumetric) in NIfTI format. Retrieved from https://doi.org /10.6084/m9.figshare.3501911.v5.

Arbib, M. A., Billard, A., Iacoboni, M., \& Oztop, E. (2000). Synthetic brain imaging: Grasping, mirror neurons and imitation. Neural Networks, 13, 975-997. DOI: https://doi .org/10.1016/s0893-6080(00)00070-8, PMID: 11156205

Balleine, B. W., \& Dickinson, A. (1998). Goal-directed instrumental action: Contingency and incentive learning and their cortical substrates. Neuropharmacology, 37, 407-419. DOI: https://doi.org/10.1016/s0028-3908(98)00033-1

Bernstein, N. (1967). The co-ordination and regulation of movements. New York: Pergamon Press.

Binkofski, F., \& Buxbaum, L. J. (2013). Two action systems in the human brain. Brain and Language, 127, 222-229. DOI: https://doi.org/10.1016/j.bandl.2012.07.007, PMID: 22889467, PMCID: PMC 4311762

Bracci, S., Caramazza, A., \& Peelen, M. V. (2018). View-invariant representation of hand postures in the human lateral occipitotemporal cortex. Neuroimage, 181, 446-452. DOI: https://doi.org/10.1016/j.neuroimage.2018.07.001, PMID: 30033392

Bracci, S., Ietswaart, M., Peelen, M. V., \& Cavina-Pratesi, C. (2010). Dissociable neural responses to hands and non-hand body parts in human left extrastriate visual cortex. Journal of Neurophysiology, 103, 3389-3397. DOI: https://doi.org/10 .1152/jn.00215.2010, PMID: 20393066, PMCID: PMC2888254

Bracci, S., \& Peelen, M. V. (2013). Body and object effectors: The organization of object representations in high-level visual cortex reflects body-object interactions. Journal of Neuroscience, 33, 18247-18258. DOI: https://doi.org/10 .1523/jneurosci.1322-13.2013, PMID: 24227734, PMCID: PMC6619748

Bub, D. N., \& Masson, M. E. J. (2010). Grasping beer mugs: On the dynamics of alignment effects induced by handled objects. Journal of Experimental Psychology: Human Perception and Performance, 36, 341-358. DOI: https://doi .org/10.1037/a0017606, PMID: 20364923

Bub, D. N., Masson, M. E. J., \& Kumar, R. (2018). Time course of motor affordances evoked by pictured objects and words.
Journal of Experimental Psychology: Human Perception and Performance, 44, 53-68. DOI: https://doi.org/10.1037 /xhp0000431, PMID: 28447845

Bub, D. N., Masson, M. E. J., \& van Noordenne, M. (2021). Motor representations evoked by objects under varying action intentions. Journal of Experimental Psychology: Human Perception and Performance, 47, 53-80. DOI: https://doi.org/10.1037/xhp0000876, PMID: 32969689

Chao, L. L., Haxby, J. V., \& Martin, A. (1999). Attribute-based neural substrates in temporal cortex for perceiving and knowing about objects. Nature Neuroscience, 2, 913-919. DOI: https://doi.org/10.1038/13217, PMID: 10491613

Chao, L. L., \& Martin, A. (2000). Representation of manipulable man-made objects in the dorsal stream. Neuroimage, 12, 478-484. DOI: https://doi.org/10.1006/nimg.2000.0635, PMID: 10988041

Cho, D. T., \& Proctor, R. W. (2013). Object-based correspondence effects for action-relevant and surface-property judgments with keypress responses: Evidence for a basis in spatial coding. Psychological Research, 77, 618-636. DOI: https://doi.org/10 .1007/s00426-012-0458-4, PMID: 23099639

Chong, I., \& Proctor, R. W. (2020). On the evolution of a radical concept: Affordances according to Gibson and their subsequent use and development. Perspectives on Psychological Science, 15, 117-132. DOI: https://doi.org/10.1177/1745691619868207, PMID: 31711365

Cisek, P. (2005). Neural representations of motor plans, desired trajectories, and controlled objects. Cognitive Processing, 6, 15-24. DOI: https://doi.org/10.1007/s10339-004-0046-7

Cisek, P. (2007). Cortical mechanisms of action selection: The affordance competition hypothesis. Philosophical Transactions of the Royal Society of London, Series B, Biological Sciences, 362, 1585-1599. DOI: https://doi.org/10.1098/rstb.2007.2054, PMID: 17428779, PMCID: PMC2440773

Cisek, P., \& Kalaska, J. F. (2005). Neural correlates of reaching decisions in dorsal premotor cortex: Specification of multiple direction choices and final selection of action. Neuron, 45 , 801-814. DOI: https://doi.org/10.1016/j.neuron.2005.01.027, PMID: 15748854

Cisek, P., \& Kalaska, J. F. (2010). Neural mechanisms for interacting with a world full of action choices. Annual Review of Neuroscience, 33, 269-298. DOI: https://doi.org/10.1146 /annurev.neuro.051508.135409, PMID: 20345247

Craighero, L., Fadiga, L., Umiltà, C. A., \& Rizzolatti, G. (1996). Evidence for visuomotor priming effect. NeuroReport, 8 , 347-349. DOI: https://doi.org/10.1097/00001756-199612200 -00068, PMID: 9051808

Creem, S. H., \& Proffitt, D. R. (2001). Grasping objects by their handles: A necessary interaction between cognition and action. Journal of Experimental Psychology: Human Perception and Performance, 27, 218-228. DOI: https://doi .org/10.1037/0096-1523.27.1.218, PMID: 11248935

Culham, J. C. (2004). Human brain imaging reveals a parietal area specialized for grasping. In N. Kanwisher \& J. Duncan (Eds.), Attention and performance XX: Functional brain imaging of visual cognition (pp. 417-438). Oxford: Oxford University Press.

Daprati, E., \& Sirigu, A. (2006). How we interact with objects: Learning from brain lesions. Trends in Cognitive Sciences, 10, 265-270. DOI: https://doi.org/10.1016/j.tics.2006.04.005, PMID: 16678468

Dolan, R. J., \& Dayan, P. (2013). Goals and habits in the brain. Neuron, 80, 312-325. DOI: https://doi.org/10.1016/j.neuron 2013.09.007, PMID: 24139036, PMCID: PMC3807793

Dolan, R. J., Fink, G. R., Rolls, E., Booth, M., Holmes, A., Frackowiak, R. S., et al. (1997). How the brain learns to see objects and faces in an impoverished context. Nature, 389 , 596-599. DOI: https://doi.org/10.1038/39309, PMID: 9335498 
Drummond, N., \& Niv, Y. (2020). Model-based decision making and model-free learning. Current Biology, 30, R860-R865. DOI: https://doi.org/10.1016/j.cub.2020.06.051, PMID: 32750340

Eickhoff, S. B., Stephan, K. E., Mohlberg, H., Grefkes, C., Fink, G. R., Amunts, K., et al. (2005). A new SPM toolbox for combining probabilistic cytoarchitectonic maps and functional imaging data. Neuroimage, 25, 1325-1335. DOI: https://doi.org/10.1016/j.neuroimage.2004.12.034, PMID: 15850749

Fagg, A. H., \& Arbib, M. A. (1998). Modeling parietal-premotor interactions in primate control of grasping. Neural Networks, 11, 1277-1303. DOI: https://doi.org/10.1016/s0893-6080(98) 00047-1, PMID: 12662750

Friston, K. J., Buechel, C., Fink, G. R., Morris, J., Rolls, E., \& Dolan, R. J. (1997). Psychophysiological and modulatory interactions in neuroimaging. Neuroimage, 6, 218-229. DOI: https://doi.org/10.1006/nimg.1997.0291, PMID: 9344826

Friston, K. J., Holmes, A. P., Worsley, K. J., Poline, J.-P., Frith, C. D., \& Frackowiak, R. S. J. (1994). Statistical parametric maps in functional imaging: A general linear approach. Human Brain Mapping, 2, 189-210. DOI: https://doi.org/10.1002/hbm .460020402

Friston, K. J., Shiner, T., FitzGerald, T., Galea, J. M., Adams, R., Brown, H., et al. (2012). Dopamine, affordance and active inference. PLoS Computational Biology, 8, e1002327. DOI: https://doi.org/10.1371/journal.pcbi.1002327, PMID: 22241972, PMCID: PMC3252266

Gallivan, J. P., McLean, D. A., Flanagan, J. R., \& Culham, J. C. (2013). Where one hand meets the other: Limb-specific and action-dependent movement plans decoded from preparatory signals in single human frontoparietal brain areas. Journal of Neuroscience, 33, 1991-2008. DOI: https://doi.org/10 .1523/jneurosci.0541-12.2013, PMID: 23365237, PMCID: PMC6619126

Gallivan, J. P., McLean, D. A., Smith, F. W., \& Culham, J. C. (2011) Decoding effector-dependent and effector-independent movement intentions from human parieto-frontal brain activity. Journal of Neuroscience, 31, 17149-17168. DOI: https:/doi .org/10.1523/jneurosci.1058-11.2011, PMID: 22114283, PMCID: PMC6623835

Gallivan, J. P., McLean, D. A., Valyear, K. F., \& Culham, J. C. (2013). Decoding the neural mechanisms of human tool use. elife, 2, e00425. DOI: https://doi.org/10.7554/eLife.00425, PMID: 23741616, PMCID: PMC3667577

Gentilucci, M. (2002). Object motor representation and reaching-grasping control. Neuropsychologia , 40, 1139-1153. DOI: https://doi.org/10.1016/s0028-3932(01)00233-0, PMID: 11931918

Gentilucci, M., \& Gangitano, M. (1998). Influence of automatic word reading on motor control. European Journal of Neuroscience, 10, 752-756. DOI: https://doi.org/10.1046/j .1460-9568.1998.00060.x, PMID: 9749737

Gibson, J. J. (1979). The ecological approach to visual perception. Boston: Houghton Mifflin.

Glasser, M. F., Coalson, T. S., Robinson, E. C., Hacker, C. D., Harwell, J., Yacoub, E., et al. (2016). A multi-modal parcellation of human cerebral cortex. Nature, 536, 171-178. DOI: https://doi.org/10.1038/nature18933, PMID: 27437579 , PMCID: PMC4990127

Gomez, M. A., Skiba, R. M., \& Snow, J. C. (2018). Graspable objects grab attention more than images do. Psychological Science, 29, 206-218. DOI: https://doi.org/10.1177 /0956797617730599, PMID: 29215960, PMCID: PMC5809313

Goodale, M. A., \& Milner, A. D. (1992). Separate visual pathways for perception and action. Trends in Neurosciences, 15, 20-25. DOI: https://doi.org/10.1016/0166-2236(92)90344-8, PMID: 1374953
Grafton, S. T., Fagg, A. H., \& Arbib, M. A. (1998). Dorsal premotor cortex and conditional movement selection: A PET functional mapping study. Journal of Neurophysiology, 79, 1092-1097. DOI: https://doi.org/10.1152/jn.1998.79.2.1092, PMID: 9463464

Grèzes, J., \& Decety, J. (2002). Does visual perception of object afford action? Evidence from a neuroimaging study.

Neuropsychologia, 40, 212-222. DOI: https://doi.org/10.1016 /s0028-3932(01)00089-6, PMID: 11640943

Grèzes, J., Tucker, M., Armony, J., Ellis, R., \& Passingham, R. E. (2003). Objects automatically potentiate action: An fMRI study of implicit processing. European Journal of Neuroscience, 17, 2735-2740. DOI: https://doi.org/10.1046/j.1460-9568.2003 .02695.x, PMID: 12823480

Grol, M. J., Majdandzić, J., Stephan, K. E., Verhagen, L., Dijkerman, H. C., Bekkering, H., et al. (2007). Parieto-frontal connectivity during visually guided grasping. Journal of Neuroscience, 27 , 11877-11887. DOI: https://doi.org/10.1523/jneurosci.3923-07 .2007, PMID: 17978028, PMCID: PMC2703728

Hardwick, R. M., Forrence, A. D., Krakauer, J. W., \& Haith, A. M. (2019). Time-dependent competition between goal-directed and habitual response preparation. Nature Human Behaviour, 3, 1252-1262. DOI: https://doi.org/10.1038/s41562-019-0725-0, PMID: 31570762

Harris, C. M., \& Wolpert, D. M. (1998). Signal-dependent noise determines motor planning. Nature, 394, 780-784. DOI: https://doi.org/10.1038/29528, PMID: 9723616

Herbort, O., \& Butz, M. V. (2011). Habitual and goal-directed factors in (everyday) object handling. Experimental Brain Research, 213, 371-382. DOI: https://doi.org/10.1007/s00221 -011-2787-8, PMID: 21748333

Herbort, O., Mathew, H., \& Kunde, W. (2017). Habit outweighs planning in grasp selection for object manipulation. Cognitive Psychology, 92, 127-140. DOI: https://doi.org/10 .1016/j.cogpsych.2016.11.008, PMID: 27951435

Holler, D. E., Fabbri, S., \& Snow, J. C. (2020). Object responses are highly malleable, rather than invariant, with changes in object appearance. Scientific Reports, 10, 4654. DOI: https:// doi.org/10.1038/s41598-020-61447-8, PMID: 32170123, PMCID: PMC7070005

Humphreys, G. W., Yoon, E. Y., Kumar, S., Lestou, V., Kitadono, K., Roberts, K. L., et al. (2010). The interaction of attention and action: From seeing action to acting on perception. British Journal of Psychology, 101, 185-206. DOI: https:/doi .org/10.1348/000712609X458927, PMID: 19619392

Kanwisher, N., Stanley, D., \& Harris, A. (1999). The fusiform face area is selective for faces not animals. NeuroReport, 10, 183-187. DOI: https://doi.org/10.1097/00001756-199901180 -00035, PMID: 10094159

Keele, S. W. (1968). Movement control in skilled motor performance. Psychological Bulletin, 70, 387-403. DOI: https://doi.org/10.1037/h0026739

Kornblum, S., \& Lee, J. W. (1995). Stimulus-response compatibility with relevant and irrelevant stimulus dimensions that do and do not overlap with the response. Journal of Experimental Psychology: Human Perception and Performance, 21, 855-875. DOI: https://doi.org/10.1037/0096 -1523.21.4.855, PMID: 7643052

Kumar, S., Yoon, E. Y., \& Humphreys, G. W. (2012). Perceptual and motor-based responses to hand actions on objects: Evidence from ERPs. Experimental Brain Research, 220, 153-164. DOI: https://doi.org/10.1007/s00221-012-3126-4, PMID: 22644235

Lee, C.-I., Mirman, D., \& Buxbaum, L. J. (2014). Abnormal dynamics of activation of object use information in apraxia: Evidence from eyetracking. Neuropsychologia , 59, 13-26. DOI: https://doi.org/10.1016/j.neuropsychologia.2014.04 .004, PMID: 24746946, PMCID: PMC4096147 
Lingnau, A., \& Downing, P. E. (2015). The lateral occipitotemporal cortex in action. Trends in Cognitive Sciences, 19, 268-277. DOI: https://doi.org/10.1016/j.tics.2015.03.006, PMID: 25843544

Mahon, B. Z., Milleville, S. C., Negri, G. A. L., Rumiati, R. I., Caramazza, A., \& Martin, A. (2007). Action-related properties shape object representations in the ventral stream. Neuron, 55, 507-520. DOI: https://doi.org/10.1016/j.neuron.2007.07 011, PMID: 17678861, PMCID: PMC2000824

Masson, M. E. J., Bub, D. N., \& Breuer, A. T. (2011). Priming of reach and grasp actions by handled objects. Journal of Experimental Psychology: Human Perception and Performance, 37, 1470-1484. DOI: https://doi.org/10.1037 /a0023509, PMID: 21553988

McBride, J., Sumner, P., \& Husain, M. (2012). Conflict in object affordance revealed by grip force. Quarterly Journal of Experimental Psychology, 65, 13-24. DOI: https://doi.org/10 .1080/17470218.2011.588336, PMID: 21824035, PMCID: PMC3259623

Nachev, P., Kennard, C., \& Husain, M. (2008). Functional role of the supplementary and pre-supplementary motor areas. Nature Reviews Neuroscience, 9, 856-869. DOI: https://doi .org/10.1038/nrn2478, PMID: 18843271

Ossmy, O., Kaplan, B., Han, D., Xu, M., Bianco, C., Mukamel, R., et al. (2020). Planning to plan: Real-time processes in the development of problem solving. PsyArXiv. DOI: https://doi .org/10.31234/osf.io/3q8p2

Owen, A. M. (1997). Cognitive planning in humans: Neuropsychological, neuroanatomical and neuropharmacological perspectives. Progress in Neurobiology, 53, 431-450. DOI: https://doi.org/10.1016 /s0301-0082(97)00042-7, PMID: 9421831

Pazzaglia, M., \& Galli, G. (2019). Action observation for neurorehabilitation in apraxia. Frontiers in Neurology, 10, 309. DOI: https://doi.org/10.3389/fneur.2019.00309, PMID: 31001194, PMCID: PMC6456663

Petrides, M. (2019). Atlas of the morphology of the buman cerebral cortex on the average MNI brain. London: Academic Press.

Pizzamiglio, G., Zhang, Z., Duta, M., \& Rounis, E. (2020). Factors influencing manipulation of a familiar object in patients with limb apraxia after stroke. Frontiers in Human Neuroscience, 13, 465. DOI: https://doi.org/10.3389/fnhum 2019.00465, PMID: 32116596, PMCID: PMC7026485

Praamstra, P., Kleine, B. U., \& Schnitzler, A. (1999). Magnetic stimulation of the dorsal premotor cortex modulates the Simon effect. NeuroReport, 10, 3671-3674. DOI: https://doi .org/10.1097/00001756-199911260-00038, PMID: 10619664

Rice, N. J., Valyear, K. F., Goodale, M. A., Milner, A. D., \& Culham, J. C. (2007). Orientation sensitivity to graspable objects: An fMRI adaptation study. Neuroimage, 36(Suppl. 2), T87-T93. DOI: https://doi.org/10.1016/j.neuroimage.2007.03 .032, PMID: 17499174

Riddoch, M. J., Edwards, M. G., Humphreys, G. W., West, R., \& Heafield, T. (1998). Visual affordances direct action: Neuropsychological evidence from manual interference. Cognitive Neuropsychology, 15, 645-683. DOI: https://doi .org/10.1080/026432998381041, PMID: 22448840

Rizzolatti, G., \& Matelli, M. (2003). Two different streams form the dorsal visual system: Anatomy and functions. Experimental Brain Research, 153, 146-157. DOI: https:// doi.org/10.1007/s00221-003-1588-0, PMID: 14610633

Rosenbaum, D. A., Marchak, F., Barnes, H. J., Vaughan, J., Slotta, J. D., \& Jorgensen, M. J. (1990). Constraints for action selection: Overhand versus underhand grips. In M. Jeannerod (Ed.), Attention and performance 13: Motor representation and control (pp. 321-342). Hillsdale, NJ: Lawrence Erlbaum Associates, Inc. DOI: https://doi.org/10.4324/9780203772010-10
Rosenbaum, D. A., Vaughan, J., Barnes, H. J., \& Jorgensen, M. J. (1992). Time course of movement planning: Selection of handgrips for object manipulation. Journal of Experimental Psychology: Learning, Memory, and Cognition, 18, 1058-1073. DOI: https://doi.org/10.1037/0278-7393.18.5.1058

Rounis, E., \& Humphreys, G. W. (2015). Limb apraxia and the "affordance competition hypothesis". Frontiers in Human Neuroscience, 9, 429. DOI: https://doi.org/10.3389/fnhum .2015.00429, PMID: 26283948, PMCID: PMC 4516886

Rounis, E., van Polanen, V., \& Davare, M. (2018). A direct effect of perception on action when grasping a cup. Scientific Reports, 8, 171. DOI: https://doi.org/10.1038/s41598-017 -18591-5, PMID: 29317763, PMCID: PMC5760564

Rounis, E., Yarrow, K., \& Rothwell, J. C. (2007). Effects of rTMS conditioning over the fronto-parietal network on motor versus visual attention. Journal of Cognitive Neuroscience, 19, 513-524. DOI: https://doi.org/10.1162/jocn.2007.19.3 .513, PMID: 17335398

Rounis, E., Zhang, Z., Pizzamiglio, G., Duta, M., \& Humphreys, G. W. (2017). Factors influencing planning of a familiar grasp to an object: What it is to pick a cup. Experimental Brain Research, 235, 1281-1296. DOI: https://doi.org/10.1007 /s00221-017-4883-x, PMID: 28204861, PMCID: PMC5348548

Rushworth, M. F., Ellison, A., \& Walsh, V. (2001). Complementary localization and lateralization of orienting and motor attention. Nature Neuroscience, 4, 656-661. DOI: https://doi.org/10.1038/88492, PMID: 11369949

Rushworth, M. F., Nixon, P. D., Renowden, S., Wade, D. T., \& Passingham, R. E. (1997). The left parietal cortex and motor attention. Neuropsychologia, 35, 1261-1273. DOI: https:// doi.org/10.1016/s0028-3932(97)00050-X, PMID: 9364496

Sakreida, K., Effnert, I., Thill, S., Menz, M. M., Jirak, D., Eickhoff, C. R., et al. (2016). Affordance processing in segregated parieto-frontal dorsal stream sub-pathways. Neuroscience and Biobehavioral Reviews, 69, 89-112. DOI: https://doi.org/10.1016/j.neubiorev.2016.07.032, PMID: 27484872

Shallice, T., Burgess, P. W., Schon, F., \& Baxter, D. M. (1989). The origins of utilization behaviour. Brain, 112, 1587-1598. DOI: https://doi.org/10.1093/brain/112.6.1587, PMID: 2597999

Simon, J. R. (1969). Reactions toward the source of stimulation. Journal of Experimental Psychology, 81, 174-176. DOI: https://doi.org/10.1037/h0027448, PMID: 5812172

Snow, J. C., Pettypiece, C. E., McAdam, T. D., McLean, A. D., Stroman, P. W., Goodale, M. A., et al. (2011). Bringing the real world into the fMRI scanner: Repetition effects for pictures versus real objects. Scientific Reports, 1, 130. DOI: https:// doi.org/10.1038/srep00130, PMID: 22355647, PMCID: PMC3216611

Till, B. C., Masson, M. E. J., Bub, D. N., \& Driessen, P. F. (2014). Embodied effects of conceptual knowledge continuously perturb the hand in flight. Psychological Science, 25, 1637-1648. DOI: https://doi.org/10.1177/0956797614538842, PMID: 24986854

Tucker, M., \& Ellis, R. (1998). On the relations between seen objects and components of potential actions. Journal of Experimental Psychology: Human Perception and Performance, 24, 830-846. DOI: https://doi.org/10.1037 /0096-1523.24.3.830, PMID: 9627419

Tucker, M., \& Ellis, R. (2001). The potentiation of grasp types during visual object categorization. Visual Cognition, 8 , 769-800. DOI: https://doi.org/10.1080/13506280042000144

Valyear, K. F., Cavina-Pratesi, C., Stiglick, A. J., \& Culham, J. C. (2007). Does tool-related fMRI activity within the intraparietal sulcus reflect the plan to grasp? Neuroimage, 36(Suppl. 2), T94-T108. DOI: https://doi.org/10.1016/j.neuroimage.2007 .03.031, PMID: 17499175 
van Elk, M., van Schie, H., \& Bekkering, H. (2014). Action semantics: A unifying conceptual framework for the selective use of multimodal and modality-specific object knowledge. Physics of Life Reviews, 11, 220-250. DOI: https://doi.org/10 .1016/j.plrev.2013.11.005, PMID: 24461373

van Polanen, V., \& Davare, M. (2015). Interactions between dorsal and ventral streams for controlling skilled grasp.

Neuropsychologia , 79, 186-191. DOI: https://doi.org/10.1016 /j.neuropsychologia.2015.07.010, PMID: 26169317, PMCID: PMC4678292

Verhagen, L., Dijkerman, H. C., Medendorp, W. P., \& Toni, I. (2012). Cortical dynamics of sensorimotor integration during grasp planning. Journal of Neuroscience, 32, 4508-4519. DOI: https://doi.org/10.1523/jneurosci.5451-11.2012, PMID: 22457498, PMCID: PMC6622056

Waszak, F., Wascher, E., Keller, P., Koch, I., Aschersleben, G., Rosenbaum, D. A., et al. (2005). Intention-based and stimulus-based mechanisms in action selection. Experimental Brain Research, 162, 346-356. DOI: https:// doi.org/10.1007/s00221-004-2183-8, PMID: 15599722

Watson, C. E., \& Buxbaum, L. J. (2015). A distributed network critical for selecting among tool-directed actions. Cortex, 65 , 65-82. DOI: https://doi.org/10.1016/j.cortex.2015.01.007, PMID: 25681649, PMCID: PMC 4385438

Wilf, M., Holmes, N. P., Schwartz, I., \& Makin, T. R. (2013). Dissociating between object affordances and spatial compatibility effects using early response components. Frontiers in Psychology, 4, 591. DOI: https://doi.org/10.3389 /fpsyg.2013.00591, PMID: 24027552, PMCID: PMC3761160
Wolpe, N., Hezemans, F. H., \& Rowe, J. B. (2020). Alien limb syndrome: A Bayesian account of unwanted actions. Cortex, 127, 29-41. DOI: https://doi.org/10.1016/j.cortex.2020.02 .002, PMID: 32155475, PMCID: PMC7212084

Wolpert, D. M. (1997). Computational approaches to motor control. Trends in Cognitive Sciences, 1, 209-216. DOI: https:// doi.org/10.1016/s1364-6613(97)01070-x, PMID: 21223909

Wong, A. L., Haith, A. M., \& Krakauer, J. W. (2015). Motor planning. Neuroscientist, 21, 385-398. DOI: https://doi.org /10.1177/1073858414541484, PMID: 24981338

Wurm, M. F., Caramazza, A., \& Lingnau, A. (2017). Action categories in lateral occipitotemporal cortex are organized along sociality and transitivity. Journal of Neuroscience, 37 , 562-575. DOI: https://doi.org/10.1523/jneurosci.1717-16 .2016, PMID: 28100739, PMCID: PMC6596756

Xia, M., Wang, J., \& He, Y. (2013). BrainNet Viewer: A network visualization tool for human brain connectomics. PLoS One, 8, e68910. DOI: https://doi.org/10.1371/journal.pone .0068910, PMID: 23861951, PMCID: PMC3701683

Zimmermann, M., Mars, R. B., de Lange, F. P., Toni, I., \& Verhagen, L. (2018). Is the extrastriate body area part of the dorsal visuomotor stream? Brain Structure and Function, 223, 31-46. DOI: https://doi.org/10.1007/s00429-017-1469-0, PMID: 28702735, PMCID: PMC5772142

Zimmermann, M., Toni, I., \& de Lange, F. P. (2013). Body posture modulates action perception. Journal of Neuroscience, 33, 5930-5938. DOI: https://doi.org/10.1523 jneurosci.5570-12.2013, PMID: 23554475, PMCID: PMC6618930 